BMJ Open

Diabetes

Research

\& Care

\section{Clinical implication of blood glucose monitoring in general dental offices: the Ehime Dental Diabetes Study}

To cite: Harase T, Nishida W, Hamakawa T, et al. Clinical implication of blood glucose monitoring in general dental offices: the Ehime Dental Diabetes Study. BMJ Open Diabetes Research and Care 2015;3:e000151.

doi:10.1136/bmjdrc-2015000151

$\mathrm{TaH}, \mathrm{WN}$, and $\mathrm{ToH}$ contributed equally.

Received 21 August 2015 Revised 7 October 2015 Accepted 23 October 2015

\section{CrossMark}

${ }^{1}$ Ehime Dental Diabetes Study Group, Ehime, Japan

${ }^{2}$ Department of Dentistry and Oral Surgery, Matsuyama Red Cross Hospital, Ehime, Japan ${ }^{3}$ Department of Oral and Maxillofacial Surgery, Ehime University Graduate School of Medicine, Ehime, Japan ${ }^{4}$ Department of Diabetes and Molecular Genetics, Ehime University Graduate School of Medicine, Ehime, Japan

Correspondence to Dr Satoshi Hino;

sahino@m.ehime-u.ac.jp

\section{ABSTRACT}

Objective: We examined whether general dentists can contribute to the detection of patients with undiagnosed diabetes and prediabetes by monitoring blood glucose in dental clinics.

Research design and methods: A total of 716 patients who visited clinics for dental treatment were enrolled and classified into 3 groups (mild, moderate, and severe) according to Kornman's criteria for periodontitis. The correlations between the casual blood glucose level, presence or absence of the history of diabetes, and/or severity of periodontitis were evaluated.

Results: 68 patients $(9.5 \%)$ had hyperglycemia (blood glucose $\geq 200 \mathrm{mg} / \mathrm{dL}$ ). Of these patients, $20(29.4 \%)$ did not have a history of diabetes. Blood glucose tended to be higher with greater periodontitis severity. Of the 3 groups, the severe periodontitis group had the highest proportion of patients with hyperglycemia $(p<0.0001)$.

Conclusions: Patients with dental problems could be screened for diabetes, especially undiagnosed diabetes. General dentists could function as practitioners to screen for diabetes.

Trial registration number: UMIN-CTR 000014877.

The early diagnosis and treatment of diabetes is important to reduce the associated public health and economic burden, particularly because approximately half of the patients with diabetes are not aware that they have diabetes. ${ }^{1}{ }^{2}$ Owing to the increase in advanced glycation end products and change in saliva properties and composition, dental problems, primarily periodontitis and dental caries, occur in patients with diabetes; ${ }^{3}{ }^{4}$ unfortunately, the negative relationship between diabetes and dental health is not recognized by the patients with diabetes or their physicians. ${ }^{56}$ In this study, we evaluated whether general dentists can contribute to the detection of patients with undiagnosed

\section{Key messages}

- The results of our study indicate that about 1 in 10 patients visiting the dentist for dental problems has hyperglycemia (blood glucose $\geq 200 \mathrm{mg} / \mathrm{dL}$ ), regardless of the history of diabetes. Of these patients, approximately one in three had no history of diabetes.

- The enrolled patients were classified into three groups (mild, moderate, and severe) for periodontitis; the severe group had the highest proportion of patients with hyperglycemia $(p<0.0001)$.

- The prevalence of diabetes in the patients with dental issues in the present study $(23.9 \%)$ is much higher than the estimated prevalence $(7.6 \%)$ in the Japanese population. This report describes the need for general dentists to assist physicians by screening patients for hyperglycemia.

diabetes and prediabetes by monitoring blood glucose in dental clinics.

\section{RESEARCH DESIGN AND METHODS}

This study enrolled patients in Japan visiting general dentists who were members of the Ehime Dental Diabetes Study Group and had received training before starting their practice. Patients with edentulous jaws were excluded, resulting in 716 patients who agreed to participate. This study was approved by the institutional review board at Ehime University Hospital, and the study protocol was registered in the UMIN clinical trial registry (UMIN 000014877). All participants provided signed informed consent before undergoing any procedure.

A questionnaire regarding their history of diabetes mellitus (DM) was completed by all of the participants. The periodontal 
condition was assessed using periodontal pocket depth (PD) and resorption of the supporting bone. The distance from the cement-enamel junction of the tooth to the bone crest was evaluated as interproximal bone loss and calculated as the percentage of the total root length. Tooth stumps and dental implants were excluded. Patients with $\geq 20$ functional teeth $(n=528)$ were divided into three groups according to Kornman's criteria for PD and bone loss: ${ }^{7}$ no to mild periodontitis (mild), moderate periodontitis (moderate), and severe periodontitis (severe).

Samples of finger capillary blood were casually obtained from all patients. Blood glucose was measured using Precision Xceed (Abbott Diabetes Care Inc., Alameda, California, USA).

GraphPad Prism 5 (GraphPad Software Inc, San Diego, California, USA) was used for statistical analyses. The results were compared between those with (DM group) and without (non-DM group) a history of diabetes. Continuous variables were compared using $\mathrm{t}$ tests, and categorical variables were compared using $\chi^{2}$ tests. One-way analysis of variance followed by Tukey's HSD (honest significant difference) test was used to compare the differences between the three groups based on Kornman's criteria. $p$ Values $<0.05$ were considered statistically significant for all tests.

\section{RESULTS}

There were 716 patients (313 men and 403 women) who participated, with a mean age of $61.1 \pm 14.4$ years (range 21-90 years) (table 1). A history of diabetes was present in 151 patients $(21.1 \%)$. The mean blood glucose level for all of the patients was $133.0 \pm 56.0 \mathrm{mg} /$ $\mathrm{dL}$; of the 68 patients $(9.5 \%)$ with hyperglycemia $(\geq 200 \mathrm{mg} / \mathrm{dL})$ (table 1$), 20(29.4 \%)$ did not have a history of diabetes.

The mean blood glucose levels were $183.2 \pm 73.9$ and $119.6 \pm 40.8 \mathrm{mg} / \mathrm{dL}$ in the $\mathrm{DM}$ and non-DM groups, respectively $(\mathrm{p}<0.0001)$. The incidences of hyperglycemia in the DM and non-DM groups were $31.8 \%$ and $3.5 \%$, respectively $(\mathrm{p}<0.0001)$.
There were 187 patients $(35.4 \%)$ in the mild periodontitis group, 286 patients $(54.2 \%)$ in the moderate periodontitis group, and 55 patients $(10.4 \%)$ in the severe periodontitis group. The mean blood glucose levels in these groups were $110.0 \pm 41.5,137.6 \pm 57.7$, and $156.1 \pm 71.1 \mathrm{mg} / \mathrm{dL}$, respectively. The glucose level in the mild periodontitis group was significantly lower than the levels in the moderate periodontitis and severe periodontitis groups $(\mathrm{p}<0.0001)$. The glucose level in the moderate periodontitis group demonstrated a tendency to be lower than that in the severe periodontitis group $(p=0.07)$. However, the severe periodontitis group had the highest proportion of patients with hyperglycemia: $5 / 187$ patients $(2.6 \%)$ in the mild periodontitis group, $25 / 286$ patients $(8.7 \%)$ in the moderate periodontitis group, and $13 / 55$ patients $(22.8 \%)$ in the severe periodontitis group $(\mathrm{p}<0.0001)$.

\section{CONCLUSIONS}

In this study, approximately one-quarter of the patients with dental issues had diabetes, regardless of their diabetes history. Furthermore, blood glucose levels were higher with more severe periodontitis in patients without diabetes but who had hyperglycemia.

The prevalence of diabetes in the patients with dental issues in this study (171 patients; $23.9 \%$ ), as assessed by combining the patients in the DM group with those in the non-DM group with hyperglycemia, is much higher than the estimated prevalence $(7.6 \%)$ in the Japanese population aged $20-79$ years. $^{1}$ Even when comparing our sample in the same age range (20-79 years), the difference in prevalences remained unaltered $(24.2 \%$ vs $7.6 \%)$. Moreover, the incidence of hyperglycemia in the non-DM group was $3.5 \%$. Diabetes is considered as a risk factor for oral disease including periodontitis and dental caries. ${ }^{4}$ It was also shown that severe periodontitis adversely affects glycemic control in diabetes and glycemia in non-diabetes participants. ${ }^{2}$ The higher prevalence of DM and hyperglycemia in the current study population compared to the general population compared to the general population was reasonable

Table 1 Dental patients' characteristics and blood glucose data

\begin{tabular}{|c|c|c|c|c|}
\hline & \multirow[t]{2}{*}{ Total } & \multicolumn{2}{|c|}{ History of diabetes } & \multirow[b]{2}{*}{ p Value } \\
\hline & & Yes & No & \\
\hline $\mathrm{n}$ & 716 & $151(21.1)$ & 565 (78.9) & \\
\hline Female/male & $403 / 313$ & $77 / 74$ & $326 / 239$ & 0.14 \\
\hline Age (years) & $61.1 \pm 14.4$ & $66.7 \pm 9.9$ & $59.5 \pm 15.0$ & $<0.0001$ \\
\hline Blood glucose (mg/dL) & $133.0 \pm 56.0$ & $183.2 \pm 73.9$ & $119.6 \pm 40.8$ & $<0.0001$ \\
\hline Hyperglycemia ( $\geq 200$ mg/dL) & $68(9.5)$ & $48(31.8)$ & $20(3.5)$ & $<0.0001$ \\
\hline Severity of periodontitis ( $\geq 20$ functional teeth) & 528 & $94(17.8)$ & 434 (82.2) & \\
\hline Mild & $187(35.4)$ & $11(11.7)$ & $176(40.6)$ & $<0.0001$ \\
\hline Moderate & $286(54.2)$ & $65(69.1)$ & 221 (50.9) & $<0.0001$ \\
\hline Severe & $55(10.4)$ & $18(19.1)$ & $37(8.5)$ & $<0.0001$ \\
\hline
\end{tabular}

Data are represented as $n, n(\%)$, or mean \pm SD. 
because of the established relationships of diabetes with oral disease. Strauss et a ${ }^{\ominus}$ analyzed data from the National Health and Nutrition Examination Survey 2003-2004 and reported that $93.4 \%$ of patients with periodontal disease met the American Diabetes Association guidelines for diabetes screening. Barasch et $a l^{10}$ screened 418 patients in community dental practices by measuring casual blood glucose. Seventy-five patients $(18 \%)$ had a diagnosis of diabetes or prediabetes, whereas 101 patients $(24.2 \%)$ had dysglycemia $\geq 126 \mathrm{mg} / \mathrm{dL}$. Other studies reported that the prevalence of diabetes and prediabetes in the general dental offices was $30-40.7 \%$ using glycated hemoglobin $(\mathrm{HbAlc}) \geq 5.7 \% .^{11} 12$

No particular symptoms were observed in patients with hyperglycemia in the non-DM group. There were 20 patients (13 men and 7 women) with a mean age of $61.9 \pm 14.1$ (range 31-80 years). The number of their remaining teeth was $22.4 \pm 6.5$ and similar to that of other patients $(22.7 \pm 6.4)$. Of 20 patients, 13 had more than 20 teeth; $2(15.4 \%)$ in the mild periodontitis group, $9(69.2 \%)$ in the moderate periodontitis group, and $2(15.4 \%)$ in the severe periodontitis group. Consequently, a man with greater periodontitis severity might be a risk factor for hyperglycemia.

We believe that our assessment strategy for periodontal status is the most reliable of the methods that could be feasibly performed in the general dental office. We categorized participants with $\geq 20$ functional teeth, which was used as an indicator of reasonable and acceptable oral health, ${ }^{13}$ using Kornman's criteria and assessed capillary blood glucose levels. Since Kornman's method is mainly based on measuring bone loss using radiography, its advantages include low levels of human error and the reflection of the cumulative effects of periodontitis. Although clinical factors such as PD, bleeding on probing, and attachment loss are also used to evaluate periodontal status, the integrity of these data to categorize patients with periodontitis depends on the skill of operators and current periodontal condition. Gingival crevicular blood during PD measurement can be used as an alternative for finger capillary blood ${ }^{14}$ and is reportedly similar to finger capillary blood for testing blood glucose and HbAlc. ${ }^{15}$ However, gingival crevicular blood is not always observed on probing and cannot be used to monitor patients with mild periodontitis. ${ }^{14}$ Although HbA1c and high-sensitive $\mathrm{C}$ reactive protein are considered objective measures, they require assessment by a laboratory. ${ }^{16} 17$

Ten of 716 patients were treated with steroid. Their illnesses were interstitial pneumonia, autoimmune hepatitis, rheumatoid arthritis, and asthma. Of these patients, eight did not have a history of diabetes. The mean blood glucose level for 10 patients with steroid treatment was $132.1 \pm 29.6 \mathrm{mg} / \mathrm{dL}$. Although a number of appropriate patients were too small to evaluate the effect of steroid treatment on blood glucose values, it was not apparent that steroid treatment increased the blood glucose levels in our study population.
The time since the last meal was not an essential question in our study, the data from 506 patients were available to analyze. The mean time since the last meal were $3.0 \pm 1.3 \mathrm{~h}$ and $2.2 \pm 1.1 \mathrm{~h}$ in the 457 patients without hyperglycemia and the 49 patients with hyperglycemia, respectively $(p<0.0001)$. The time after a meal was a significant factor in our study to measure the casual blood glucose. Whereas testing fasting glucose is impractical in general dental offices, measuring casual blood glucose might be useful to screen hyperglycemic patients and adequate for our purpose. With consideration for a limitation of the use of casual blood glucose, general dentists would refer patients with hyperglycemia for further examination, diagnosis, and treatment to a medical office.

Periodontitis is the most prevalent chronic disease worldwide ${ }^{2}$ and many patients see their dentists more often than their primary care physicians. ${ }^{18}$ Therefore, patients seeking care for dental problems could be screened for diabetes, especially undiagnosed diabetes. Self-management practices for periodontitis, such as frequent tooth brushing to decrease dental plaque, are reportedly correlated with attitudes about diabetes. ${ }^{19}$ A dental recall system, which aims to maintain oral health after treatment completion, provides a valuable chance to monitor blood glucose on a regular basis. General dentists could function as valuable practitioners in the total healthcare system, particularly for diabetes.

Acknowledgements The authors would like to thank the participants of the Ehime Dental Diabetes Study and Editage for English language editing.

Contributors TaH, Kenji Shigematsu, SK, HS, SI, HM, KN, HI, MF, and HY collected the clinical data. TaH, WN, and ToH were primarily responsible for data collection and analysis. RK, YT, HiO, Keita Shimizu, $\mathrm{HH}$, and $\mathrm{HaO}$ contributed to the interpretation of the findings and the final editing of the manuscript. SH wrote the manuscript and is the guarantor and, as such, had full access to all the data in the study and takes responsibility for the integrity of the data and accuracy of the data analysis.

Funding This study was funded by Ehime Prefecture and the Ehime Dental Association.

Competing interests None declared.

Ethics approval The institutional review board at Ehime University Hospital.

Provenance and peer review Not commissioned; externally peer reviewed.

Data sharing statement No additional data are available.

Open Access This is an Open Access article distributed in accordance with the Creative Commons Attribution Non Commercial (CC BY-NC 4.0) license, which permits others to distribute, remix, adapt, build upon this work noncommercially, and license their derivative works on different terms, provided the original work is properly cited and the use is non-commercial. See: http:// creativecommons.org/licenses/by-nc/4.0/

\section{REFERENCES}

1. International Diabetes Federation: IDF Diabetes atlas sixth edition. http://www.idf.org/diabetesatlas (accessed 21 Jul 2015).

2. Chapple ILC, Genco R, on behalf of working group 2 of joint EFP/ AAP workshop. Diabetes and periodontal diseases: consensus report of the Joint EFP/AAP Workshop on Periodontitis and Systemic Diseases. J Clin Periodontol 2013;40(Suppl 14):S106-12. 
3. Lalla E, Lamster IB, Feit M, et al. Blockade of RAGE suppresses periodontitis-associated bone loss in diabetic mice. J Clin Invest 2000;105:1117-24.

4. Jawed M, Shahid SM, Qader SA, et al. Dental caries in diabetes mellitus: role of salivary flow rate and minerals. J Diabetes Complicat 2011;25:183-6.

5. Allen EM, Ziada HM, O'Halloran D, et al. Attitudes, awareness and oral health-related quality of life in patients with diabetes. J Oral Rehabil 2008;35:218-23.

6. Owens JB, Wilder RS, Southerland JH, et al. North Carolina internists' and endocrinologists' knowledge, opinions, and behaviors regarding periodontal disease and diabetes: need and opportunity for interprofessional education. J Dent Educ 2011;75:329-38.

7. Kornman KS, Crane A, Wang $\mathrm{H}-\mathrm{Y}$, et al. The interleukin-1 genotype as a severity factor in adult periodontal disease. J Clin Periodontol 1997;24:72-7.

8. Kuo LC, Polson AM, Kang T. Associations between periodontal diseases and systemic diseases: a review of the inter-relationships and interactions with diabetes, respiratory diseases, cardiovascular diseases and osteoporosis. Public Health 2008;122:417-33.

9. Strauss SM, Russell S, Wheeler A, et al. The dental office visit as a potential opportunity for diabetes screening: an analysis using NHANES 2003-2004 data. J Public Health Dent 2010;70:156-62.

10. Barasch A, Gilbert GH, Spurlock N, et al. for the DPBRN Collaborative Group. Random plasma glucose values measured in community dental practices: findings from The Dental Practice-Based Research Network. Clin Oral Invest 2013;17:1383-8.
11. Genco RJ, Schifferle RE, Dunford RG, et al. Screening for diabetes mellitus in dental practices: a field trial. J Am Dent Assoc 2014;145:57-64.

12. Herman WH, Taylor GW, Jacobson JJ, et al. Screening for prediabetes and type 2 diabetes in dental offices. J Public Health Dent 2015;75:175-82.

13. World Health Organization. A review of current recommendations for the organization and administration of community oral health services in northern and western Europe. Report on a WHO workshop. Oslo, 1982.

14. Strauss SM, Wheeler AJ, Russell SL, et al. The potential use of gingival crevicular blood for measuring glucose to screen for diabetes: an examination based on characteristics of the blood collection site. J Periodontol 2009;80:907-14.

15. Strauss SM, Tuthill J, Singh G, et al. A novel intra-oral diabetes screening approach in periodontal patients: results of a pilot study. $J$ Periodontol 2012;83:699-706.

16. American Diabetes Association. Diagnosis and classification of diabetes mellitus. Diabetes Care 2014;37(Suppl 1):S81-90.

17. Doi Y, Kiyohara Y, Kubo M., et al. Elevated C-reactive protein is a predictor of the development of diabetes in a general Japanese population: the Hisayama Study. Diabetes Care 2005;28:2497-500.

18. Giddon DB, Swann B, Donoff RB, et al. Dentists as oral physicians: the overlooked primary health care resource. J Primary Prevent 2013;34:279-91.

19. Syrjala A-MH, Kneckt MC, Knuuttila MLE. Dental self-efficacy as a determinant to oral health behavior, oral hygiene and $\mathrm{HbA1c}$ level among diabetic patients. J Clin Periodontol 1999;26:616-21. 